19 Revue d'histoire du XIXe siècle

Société d'histoire de la révolution de 1848 et des

révolutions du XIXe siècle

$62 \mid 2021$

Ancêtres

\title{
Thomas BOUCHET, Utopie
}

\section{Caroline Fayolle}

URL : https://journals.openedition.org/rh19/7698

DOI : $10.4000 /$ rh 19.7698

ISSN : $1777-5329$

\section{Éditeur}

La Société de 1848

\section{Édition imprimée}

Date de publication : 20 juin 2021

Pagination : 275-276

ISSN : 1265-1354

Référence électronique

Caroline Fayolle, "Thomas BOUCHET, Utopie », Revue d'histoire du XIXe siècle [En ligne], 62 | 2021, mis en ligne le 17 août 2021, consulté le 26 août 2021. URL : http://journals.openedition.org/rh19/7698 ; DOI : https://doi.org/10.4000/rh19.7698

Ce document a été généré automatiquement le 26 août 2021.

Tous droits réservés 


\title{
Thomas BOUCHET, Utopie
}

\author{
Caroline Fayolle
}

\section{RÉFÉRENCE}

Thomas BOUCHET, Utopie, Paris, Anamosa, 2021, 91 p., $9 €$.

1 La maison d'édition Anamosa propose au sein de sa collection «Le mot est faible", dirigée par Christophe Granger, de brefs essais visant à ressaisir des mots dévoyés, euphémisés, détournés, afin de restaurer leurs significations multiples et parfois leur portée subversive (de «Révolution» à "environnement» en passant par «démocratie »). C'est au tour du mot « utopie » de retrouver ses couleurs sous la plume de l'historien Thomas Bouchet, spécialiste notamment des premiers socialismes du XIX ${ }^{\mathrm{e}}$ siècle. Au fil des pages de ce petit livre roboratif, le lecteur est invité à prendre le large sur le navire Utopie, croisant sur sa route les fondateurs de ce genre littéraire né au XVI ${ }^{e}$ siècle (Thomas More, Rabelais), des socialistes du XIX ${ }^{e}$ siècle (Cabet, Fourier, Désirée Véret, Jules Gay) et des militant.es qui ont expérimenté récemment des utopies pratiques pour résister à la violence du monde (de la Zad de Notre-Dame des Landes à l'insurrection du Chiapas). L'enjeu est de « relancer le mot encore et encore, non pas pour le brandir comme un nouvel étendard mais pour maintenir vive la puissance contestataire poétique qu'il porte en lui » (p. 82).

De fait, rarement un mot n'a été aussi malmené que celui d'« utopie». Prise dans un étau, l'utopie est accusée d'être à la fois le fruit de doux rêveurs incapables de penser le principe de réalité (ce dernier venant toujours justifier le maintien des rapports de domination) et à la fois la matrice des idéologies totalitaires $d u x^{e}$ siècle. Dès le $\mathrm{XIX}^{\mathrm{e}}$ siècle, l'utopie, rapidement associée aux premiers socialismes, est mobilisée pour disqualifier tout combat contre l'inégalité et l'injustice. Des socialistes eux-mêmes condamnent ce mot, à l'image de Marx et Engels qui opposent le «socialisme scientifique » au "socialisme utopique » conçu comme une étape illusoire et dépassée de la lutte contre l'exploitation du prolétariat. Plus récemment, la publicité et le marketing dévoient à nouveau le terme devenu un pur outil de communication visant à 
inciter à toujours plus de consommation. Pourtant, s'il est sans cesse fragilisé, démagnétisé, le mot résiste.

3 C'est cette persistance de l'utopie, sa capacité à animer les imaginaires et les contestations qu'interroge Thomas Bouchet. Il s'agit, non pas de retrouver et de fixer le " vrai » sens du mot « utopie », - ce qui équivaudrait justement à le neutraliser -, mais de saisir en lui un moteur, une énergie propre à (re)mettre en mouvement la pensée et l'action. Pour cela, l'auteur consacre bien sûr une sous-partie à Fourier, penseur du mouvement et de l'« écart absolu » qui dessine une utopie à la fois sensuelle et politique fondée sur l'expression des passions humaines et leurs combinaisons harmoniques. Il rend aussi hommage aux auteurs qui puisent dans l'utopie la source d'une pensée critique comme le libertaire Joseph Déjacque, auteur de L'Humanisphère. Utopie anarchique (1858-1859), ou encore les philosophes Walter Benjamin et Ernst Bloch. Ces derniers, associant l'utopie à un messianisme revisité, cherchent à retrouver dans les utopies passées un matériel explosif pour dynamiter le cours de l'histoire et frayer de nouvelles voies émancipatrices. C'est d'ailleurs dans Le Principe espérance, titre du monumental ouvrage d'Ernst Bloch (publié de 1954 à 1959), que Thomas Bouchet trouve finalement une des clefs pour comprendre la vitalité à toute épreuve du vocable utopie. Parce que ce mot porte en lui un "anti-fatalisme» (p.62) qui vient libérer nos imaginaires politiques et nous inviter à la résistance, on a toujours besoin de l'utopie, et aujourd'hui plus que jamais. 